\title{
Vinyl chloride analysis with Solid Phase Microextraction (SPME)/GC/MS applied to analysis in materials and aqueous samples
}

\author{
R. Charvet*, C. Cun and P. Leroy \\ CRECEP-Ville de Paris, Laboratoire de Chimie Organique, 144 Ave. Paul Vaillant Couturier, 75014 Paris, France

\begin{abstract}
The increasing use of plastics in our society makes the vinyl chloride a potential source of pollution for environment. Related to its toxicity and presence in the environment, the new European Directive for drinking water quality includes now a limit for its concentration in drinking water. Currently a government needs new analytical methods to analyse this pollutant. This study concerns the optimization of the headspace solid-phase microextraction (HS-SPME) combined with gas chromatographyion trap mass spectrometry for the vinyl chloride analysis in liquid and solid samples.

The Carboxen PDMS (Polydimethylsiloxane) $75 \mu \mathrm{m}$ fibre allows a limit of detection of $50 \mathrm{ppt}$ and $100 \mathrm{ppt}$ as a limit of quantification in linearity and repeatability conditions useful for control analysis. Moreover, the excellent affinity between this fibre and the molecule of interest makes the use of little volumes of samples possible. Each parameter had been optimized to obtain the best sensibility. This method has also been applied to materials.
\end{abstract}

Keywords. Solid-Phase Microextraction - SPME - water analysis - vinyl chloride - PVC.

\section{Introduction}

Plastic materials are very useful for water conditioning and transport but they could be an important source of pollution. In the sixties, several accidents have been led to the setting up of rules on the materials composition in order to limit the potential risk of chemicals compounds migration. Among those pollution is the vinyl chloride migration, which is a constituent monomer of polyvinyl chloride (PVC) recognized as a carcinogen compound [1]. The European directive states that materials and objects mustn't give to the foods a quantity of vinyl chloride able to be detected by analytical methods that have $0.01 \mathrm{mg} / \mathrm{kg}$ as limit of detection [2]. In addition the maximal quantity of vinyl chloride contained in those materials had been established at $1 \mathrm{mg} / \mathrm{kg}$ per product [3]. Materials have to check different kind of organoleptic, analytics and cytotoxic tests $[4,5,6]$. The technique currently used for treatement is the $24 \mathrm{~h}$ soaking in a chlorinated water. Then, this water is analysed [7]. Due to its volatility ( $\mathrm{bp}=-13.5^{\circ} \mathrm{C}$ ), vinyl chloride can not be sampled by usual methods although. Headspace or purge and trap analysis can reach $10 \mathrm{ppt}$ as limit of detection with specific detector [8-11]. Their optimization for control analysis remains difficulties.

The solid-phase microextraction (SPME) method developed by Pawliszyn and co-workers $[12,13]$ has been commercialized since 1993. It appeared as an alternative technique for volatil compounds and has already found a lot of applications in environmental analysis [14], as it is rapid, automatized and solvent free. Studies about SPME in immersion gave satisfactory result [15], but the headspace technique seems more adapted to this analysis, because of the large volatility of the compounds of interest. Pawliszyn and Zhang [16] demonstrated the excellent results of SPME analysis for 28 volatiles organo-halogenated compounds (VOCs), including the vinyl chloride. This analysis was achieved by headspace extraction using PDMS $100 \mu \mathrm{m}$ fibre. Concerning the vinyl chloride, the limit of detection was $50 \mathrm{ppt}$ for a $25 \mathrm{ml}$ sample in a $40 \mathrm{ml}$ vial. Using HS-SPME, some studies demonstrated that the extraction is faster with stirring [17]. Salt saturation increases the analytes extraction as solubility decreases in aqueous phase. Moreover, concerning real samples, salt saturated solutions allow to sample at a constant ionic strength. The sodium chloride presents better capacity to advantage extraction than the other salts $[18,19]$. The recently developed Carboxen PDMS fibre, is recommended for the small volatile compounds extraction. This fibre, tested by Popp and Paschke [20] on severals VOCs proved a significant affinity for these compounds, despite of a low repetability.

This study concerns the optimization of HSSPME/GC/MS with a Carboxen PDMS fiber for the vinyl chloride extraction in smaller volumes of aqueous samples and with a best repeatability. In a second part, the aim is to develop this analytical method for materials analysis.

*Correspondence and reprints.

Received October 12, 2000; revised December 7, 2000; accepted December 18, 2000. 


\section{Experimental}

\section{Reagents, samples}

Solutions of vinyl chloride (200 mg/L in methanol) were obtained from Supelco. The first dilution was prepared by spiking of 5 to $10 \mu \mathrm{l}$ of vinyl chloride standard in $1 \mathrm{ml}$ of methanol. The serial dilutions were prepared in $\mathrm{MeOH}$ (Supelco). In $10 \mathrm{ml}$ of water, we introduced between 1 and $10 \mu \mathrm{l}$ of the diluted solution of vinyl chloride. The experiences are achieved in $16 \mathrm{ml}$ vials immediately sealed after the introduction of the spiked solution. The MilliQ water (Millipore) $\mathrm{NaCl}$ saturated samples are spiked with the standard analytes in $\mathrm{MeOH}$ (lower than $0.1 \%$ ). The $\mathrm{NaCl}$ was obtained from Merck. Every sample contains a magnetic stir bar to obtain a homogeneous stirring. The standard samples are conserved at $5{ }^{\circ} \mathrm{C}$. Depending on the considered experience, the standard concentrations range is from 0.1 to $300 \mathrm{ppb}$.

The 4 PVC materials tested (tubes and joins of pipes) have been supplied by different manufacturers. A piece of $0.6 \mathrm{~g}$ is introduced in a $16 \mathrm{ml}$ screw-vial immediately sealed and heated 2 hours in an oven at $50{ }^{\circ} \mathrm{C}$.

The 4 waters, in contact during 3 days with solid materials in a bottle of $1 \mathrm{l}$, contain $100 \mathrm{mg} / \mathrm{l}$ of chlorine. The ratio area/volume is $240 \mathrm{~cm}^{3} / 1$ without headspace to avoid most of the volatil compounds losses. $10 \mathrm{ml}$ of water were sampled and introduced in a $16 \mathrm{ml}$ vial containing $3 \mathrm{~g}$ of $\mathrm{Nacl}$ and a magnetic stir bar. The sample is stirred $100 \mathrm{~min}$ at room temperature before the extraction by the fiber.

The natural mineral and source waters, conditioned in PVC bottles, are analysed in the same conditions.

\section{Sampling devices}

\section{Fibres, SPME}

A Varian SPME 8200 CX system has been used for the analysis. The SPME module was equiped with the Autotherm system (VARIAN), which fixed the vial temperature. The different fibers tested are the PDMS $100 \mu \mathrm{m}$, PDMS $30 \mu \mathrm{m}$, PDMS $7 \mu \mathrm{m}$, PDMS DVB $65 \mu \mathrm{m}$, Carbowax/DVB $65 \mu \mathrm{m}$, Polyacrylate $85 \mu \mathrm{m}$, Carboxen PDMS $75 \mu \mathrm{m}$ (Supelco).

The SPME principle is based on the preconcentration of pollutants on the fused silica fiber coated with an organic film. The organic compounds are adsorbed on the fiber, which is introduced in either liquid or gas phase. Then this fiber is directly desorbed by thermal way in the injector of the gas chromatograph.

During this study the time required to obtain the equilibrium and the complete desorption of the fiber has been checked for the Carboxen fibre. 10 min have been kept for time adsorption and $5 \mathrm{~min}$ for time desorption. In this test these times are longer than the required time in order to limit the influence of non-controlled factors.

\section{GC/MS}

The vinyl chloride analysis is carried out in a Varian 3400 CX GC system equipped with a programmated SPI Injector.

The column and the injector temperature are both programmed and cooled with nitrogen.

The VOCs are separated on a $30 \mathrm{~m} \times 0.25 \mathrm{~mm}$ Vocol column, $1.5 \mu \mathrm{m}$ film thickness (Supelco).

During the introduction of the fiber in the injector, the column is remained at $-20{ }^{\circ} \mathrm{C}$ to improve the cryotrapping. The temperature program of the column is: $-20{ }^{\circ} \mathrm{C}$, $45^{\circ} \mathrm{C} / \mathrm{min}$ to $60{ }^{\circ} \mathrm{C}, 10{ }^{\circ} \mathrm{C} / \mathrm{min}$ to $210{ }^{\circ} \mathrm{C}$, hold $3 \mathrm{~min}$.

The rapid increase of temperature allows a good definition of the peak. The second programming allows the separation of the other VOCs.

The temperature of the injector was $210{ }^{\circ} \mathrm{C}$, which is the maximum temperature of the column. This programmation makes possible the punctual desorption of vinyl chloride and of all the adsorbed analytes.

The GC was associated with an ion-trap mass spectrometer Saturn 2000 Varian. The ion-trap was scanned in mass range $m / z=35-400$ (EI, $70 \mathrm{eV}$ electron energy, AGC mode). The trap, the manifold and the transfert line temperatures are respectively $120{ }^{\circ} \mathrm{C}, 55{ }^{\circ} \mathrm{C}$ and $140{ }^{\circ} \mathrm{C}$. The quantification is realised in TIC mode.

The mass spectrometer allows the quantification and the identification of the compounds even if the matrix is complex.

\section{Calculation methods}

Calculation methods were obtained from the French norm T 90-210 for the validating analysis method.

\section{Adjustment of the model}

A Student test ( $t$ ) is applied to check whether or not the gradient is significantly different from 0 and therefore if it has a direction. If the slope $P_{\text {value }}$ is smaller or equal than 0.05 , the zero hypothesis is rejected, and the coefficient a is significantly different from 0 . The calibration function calculated observes the model $Y=b+a X$. If the intercept $P_{\text {value }}$ is bigger than 0.05 , the zero hypothesis is accepted and the intercept is considered as equal zero.

The detection and quantification limits equations.

The detection limit is defined by the relation:

$$
\mathrm{L}_{\mathrm{D}}=Y_{\text {blank }}+K_{\mathrm{d}} s_{\text {blank }}
$$

with $K_{\mathrm{d}}=2 \sqrt{2} \times t_{1-\alpha}$ and the quantification limit is defined by the relation:

$$
\mathrm{L}_{\mathrm{Q}}=Y_{\text {blank }}+10 s_{\text {blank }}
$$




\section{Original articles}

$Y_{\text {blank }}$ is the area average of blanks and $s_{\text {blank }}$ is the standard deviation as indicated in the French norm. The blank signal is the flow disruption.

\section{The analysis of variance (ANOVA)}

We use the one-way ANOVA analysis to analyse the effect of one qualitative factor on one response variable. The design can be balanced or unbalanced; in other words, the group sizes do not have to be equal. If we are analysing the effects of two or more variables, or if we need covariates in your analysis, we use the multifactor ANOVA analysis.

\section{Comparison of slopes}

As an addition to the adjustment tests of linear models, the comparison of slopes offers a statistical assessment of the differences between the models. This comparison is performed in two stages: a study of the typical differences in gradients using a Fisher-Snedecor test $(\mathrm{F})$ and subsequently a study of the values of the gradients via the Student test (t). A pre-requisite for the Student test is the absence of any significant difference in gradient variants. The statistics calculated are compared with the values tabulated for an alpha risk of $1 \%$ for the Snedecor test and $5 \%$ for the Student test.

\section{Repeatability relation

$$
\text { C. } V=100 \times(\mathrm{Sg} / \mathrm{Yg}),
$$

with $Y \mathrm{~g}$, the average and $S \mathrm{~g}$, the standard deviation.

\section{Results}

\section{Fibers comparison}

The 7 fibers were tested with 180 ppb vinyl chloride solution to estimate which of those fibers presents the best adsorption and the best affinity in the considered conditions (Fig. 1). A minimum of the 5 runs was realised on each fiber types.

The vinyl chloride extraction by Carboxen PDMS was more important than the extraction realized with the other fibers. This fiber also allows the best limit of detection, because it presents an extraction of vinyl chloride 100 times more important than the PDMS $100 \mu \mathrm{m}$ fiber and the PDMS DVB fiber.

\section{Effect of $\mathrm{MeOH}$}

During the test with vinyl chloride and VOCs, the $\mathrm{MeOH}$ quantity seems to influence the compounds volatility. For $0.9 \mathrm{ppb}$ concentration of vinyl chloride, the extracted quantity decreases when the $\mathrm{MeOH}$ volume increases according to the equation:

$$
-375.49 x+71198
$$

( $x$ as $\mathrm{ml}$ of $\mathrm{MeOH}$ ) (Fig. 2). This phenomenon is less perceptible for more important vinyl chloride concentration,

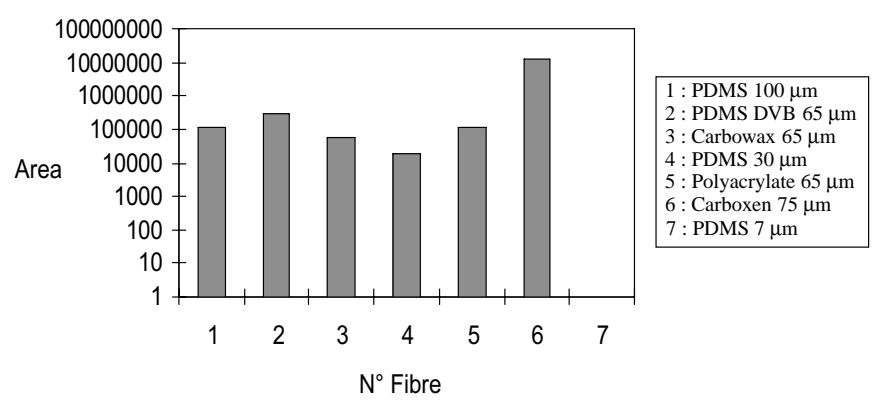

Figure 1. Comparison of recorded areas for the different fibres concerning the extraction of $180 \mathrm{ppb}$ of vinyl chloride.

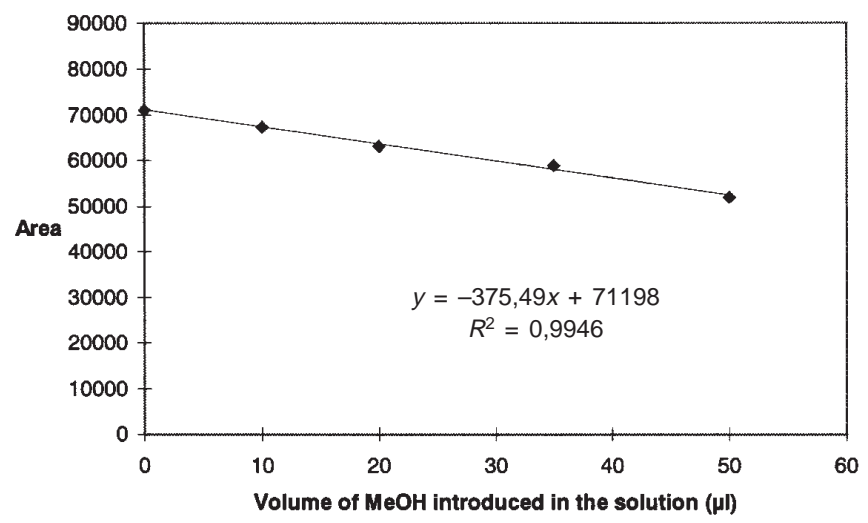

Figure 2. Adsorption profile depending on the $\mathrm{MeOH}$ quantity $(\mu \mathrm{l})$ for a $0.9 \mathrm{ppb}$ vinyl chloride concentration.

because the vinyl chloride quantity dissolved in the $\mathrm{MeOH}$ is insignificant in comparison with the quantity present in the headspace. The important quantity of $\mathrm{MeOH}$ also disturbs the other VOCs. As this solvent can limit the extraction of volatile compounds, it is important to verify its presence in real samples. To minimize this effect, the sample should contain lower than $0.1 \%$ of the standard analytes solution.

\section{The stirring time before adsorption}

It is necessary to wait for the obtention of equilibrium between liquid and gas phases before achieving the extraction by the fiber. At room temperature, the minimum average time is 100 min (Fig. 3). Below this previous analysis time, the repeatability is not satisfactory anymore. Moreover, this equilibrium must be achieved at the same temperature as the one used for the extraction.

\section{Fibre adsorption time}

This experience has been achieved with 0.9 ppb vinyl chloride concentration in a $10 \mathrm{ml}$ sample volume. When the 


\section{Original articles}

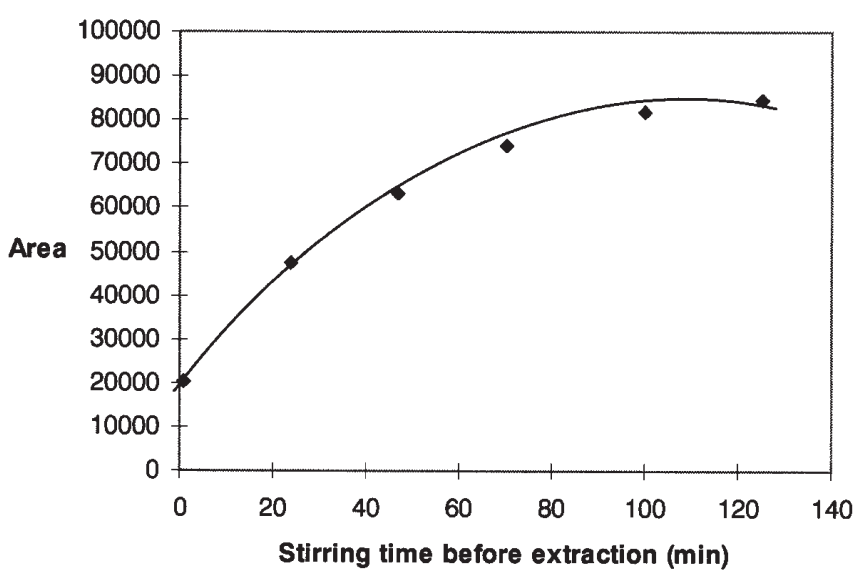

Figure 3. Adsorption profile depending on the stirring time before extraction for a 0.9 vinyl chloride concentration.

equilibrium liquid/gas is reached, the required time to obtain the equilibrium between the gas and the fiber phases is lower than 300 seconds (Fig. 4).

\section{Sample volume}

For a fixed concentration of vinyl chloride, the variation of sample volume introduced in the vial has an important influence on the extracted quantity. The extracted quantity increases with the sample volume (Fig. 5).

The sample volume should however stay below $11.5 \mathrm{ml}$ to keep the fiber away from the liquid sample.

\section{Temperature}

The extraction of the $1 \mathrm{ppb}$ solution had been observed with different temperatures between 15 and $70{ }^{\circ} \mathrm{C}$ (Fig. 6). This experience shows an optimum temperature of $20{ }^{\circ} \mathrm{C}$. When the temperature is inferior, the extraction decreases because the vinyl chloride becomes less volatile. For higher temperatures, the pressure increasing in the vial is unfavourable to the adsorption. Therefore all experiences were realised at $20{ }^{\circ} \mathrm{C}$.

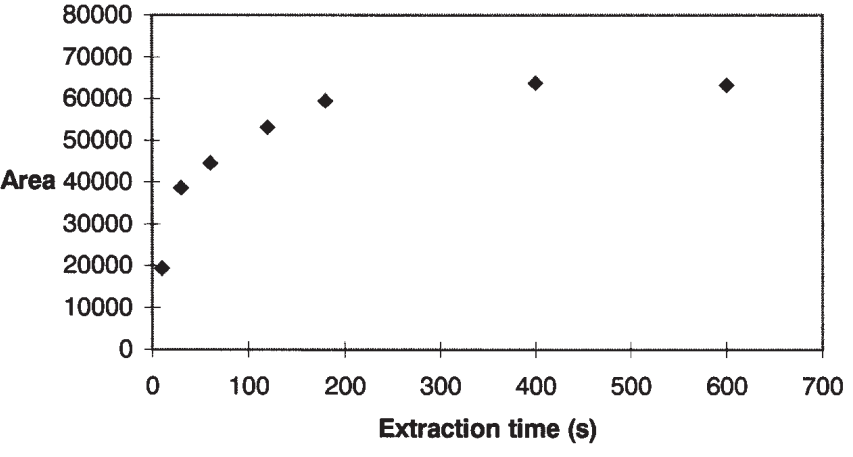

Figure 4. Profile of vinyl chloride extraction depending on extraction time.

\section{Linearity, detection and quantification limits}

\section{Linearity}

The linearity has been demonstrated on a domain of 3 size orders. The highest value is $200 \mathrm{ppb}$. There is no memory effect. Any extraction is representative of the analysed sample.

The linearity curves are achieved with one point by concentration. The analysis was performed in a random order.

The table I sums up the results of the statistical test of the linear model adjustement.

\section{Limit of detection and limit of quantification}

The determination of the detection and quantification limits was based on the results of the repeated blanks analysis, achieved under conditions of repeatability (Tab. II). The blank studies were equivalent for the 3 fibers. The blank results are given for the fiber number 3. Blanks result from the flow disturbance.

For a risk $\alpha=5 \%$, the result is $t_{1-\alpha}=t_{0.95}=1.83$ for $\mathrm{a}$ unilateral test with 9 degrees of freedom. Then, we can deduce $K_{\mathrm{d}}=5.18$.

The quantification limit is defined by the relation:

$$
\mathrm{L}_{\mathrm{Q}}=Y_{\text {blank }}+10 s_{\text {blank }} \text {. }
$$

Table I. Linearity results with 3 carboxen PDMS fibers.

\begin{tabular}{|c|c|c|c|c|c|c|c|c|c|}
\hline Fibers & Equations & $\begin{array}{c}\text { intercept } \\
\text { standard } \\
\text { error }\end{array}$ & $\begin{array}{c}\text { slope } \\
\text { standard } \\
\text { error }\end{array}$ & $\begin{array}{c}\text { Correlation } \\
\text { coefficient }\end{array}$ & $\begin{array}{c}R \text {-squared } \\
\%\end{array}$ & $\begin{array}{c}t \\
\text { slope }\end{array}$ & $P$-value & $\begin{array}{c}t \\
\text { intercept }\end{array}$ & $P$-value \\
\hline Carboxen $\mathrm{N}^{\circ} 1$ & $72966.7 x+1681.31$ & 2951.47 & 2683.16 & 0.9953 & 99.0623 & 27.1943 & 0.0000 & 0.56965 & 0.5867 \\
\hline Carboxen $\mathrm{N}^{\circ} 2$ & $83747.8 x+1502.6$ & 1407.32 & 1946.26 & 0.9986 & 99.7307 & 43.0301 & 0.0000 & 1.06771 & 0.3345 \\
\hline Carboxen $\mathrm{N}^{\circ} 3$ & $89443.9 x-3123.7$ & 1178.49 & 1974.05 & 0.9992 & 99.8541 & 45.3099 & 0.0000 & -2.6505 & 0.0770 \\
\hline
\end{tabular}




\section{Original articles}

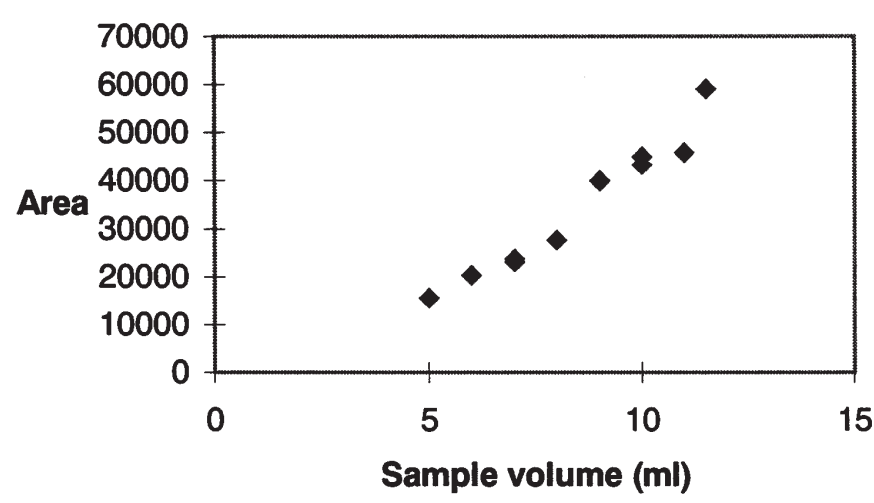

Figure 5. Profile of extraction of 0.9 ppb vinyl chloride depending on the sample volume.

Table II. Detection and quantification limits results.

\begin{tabular}{lcc}
\hline Fibres & $\begin{array}{c}\text { Detection limit } \\
(p p t)\end{array}$ & $\begin{array}{c}\text { Quantification limit } \\
(p p t)\end{array}$ \\
\hline Carboxen $\mathrm{N}^{\circ} 1$ & 52.5 & 96.3 \\
Carboxen $\mathrm{N}^{\circ} 2$ & 47.9 & 86 \\
Carboxen $\mathrm{N}^{\circ} 3$ & 96 & 132 \\
Average & 65.5 & 104.7 \\
Standard deviation & 26.53 & 24.14 \\
\hline
\end{tabular}

Out of 10 measures of blank we obtain:

$$
Y_{\text {blank }}=2079.3 \text { et } s_{\text {blank }}=663.309 \text {. }
$$

The detection limit is estimated at $65.5 \pm 48.7 \mathrm{ppt}$, and the quantification limit at $104.7 \pm 44$ ppt. Considering the short retention time of the vinyl chloride, there are little background noises and interferents. It allows 50 ppt and $100 \mathrm{ppt}$ for the detection and quantification limits.

The confident interval is calculated on the relation:

$$
Y \pm \mathrm{t}_{0.975} \times \frac{S}{\sqrt{n}} \text { with } \mathrm{t}_{0.975}=3.18
$$

\section{Specificity}

The study of the specificity of 3 carboxen fibres responses has been achieved during the vinyl chloride linearity study

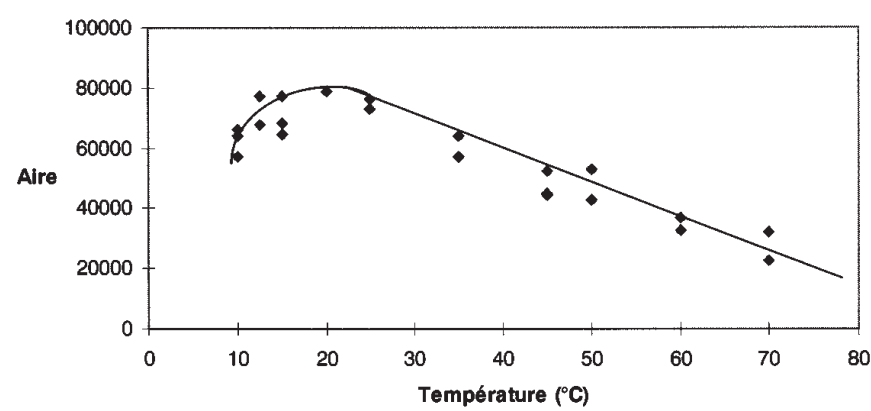

Figure 6. Profile of extraction of 1 ppb vinyl chloride depending on the temperature.

(Tab. III). The extraction and analysis conditions are considered to be repeatable.

If the P-value of the F-test is upper or equivalent to 0.05 , then there is statistically no significant difference between the 3 fibres at the 95,0\% confidence level.

\section{$F$ test on the model and $t$ test on the slope.}

In any case, the calculated values are lower than the statistically tabulated values. Hence, the null hypothesis can be rejected. The linear models comparison by pair shows no statistically significative differences (Tab. IV).

\section{Repeatability}

The response repeatability for the whole analysis of one fiber with different vinyl chloride spiking levels was controlled with CV \% (Tab. V).

$$
C . V=100 \times(\mathrm{Sg} / \mathrm{Yg}) .
$$

Hence, this method presents a satisfactory repeatability in the 0.2 to $20 \mathrm{ppb}$ concentration range.

\section{Interferent compounds}

The environmental water is often a very polluted matrix. An experience has evaluated the consequences of the other volatile organo-halogenated compounds (VOCs) presence on the quality of the vinyl chloride extraction. Variable concentrations of the VOCs used for sanitary control in the laboratory were introduced in a $20 \mathrm{ppb}$ spiked solution of vinyl chloride (Tab. VI). The extraction of vinyl chloride was the

Table III. ANOVA table (analysis of variance) for the 3 fibres with 0.1 to 2 ppb concentration range.

\begin{tabular}{lcccc}
\hline Source of error & Sum of square & $D f$ & Mean Square & F-ratio \\
\hline Between groups & $1.855 \times 10^{9}$ & 2 & $9.279 \times 10^{8}$ & 0.56 \\
Within groups & $2.9961 \times 10^{10}$ & 18 & $1.6645 \times 10^{9}$ & \\
Total (corr.) & $3.18117 \times 10^{10}$ & 20 & & \\
\hline
\end{tabular}




\section{Original articles}

Table IV. Statistical tests results on the slope values and standard deviations of the 3 tested fibres.

Test $F$ of Snedecor

Test $t$ of Student

\begin{tabular}{lcccccccc} 
Fibres & Standard Deviation & $F_{\text {calculated }}$ & $D F$ & $F_{0.995}$ & Slope Values & $t_{\text {calculated }}$ & $D F$ & $t_{0.975}$ \\
\hline $\mathrm{N}^{\circ} 1$ & 2683.16 & 1.9 & 7 & 14.2 & 72966.7 & 0.871 & 10 & 2.23 \\
$\mathrm{~N}^{\circ} 2$ & 1946.26 & & 5 & & 83747.8 & & & \\
$\mathrm{~N}^{\circ} 1$ & 2683.16 & 1.378 & 7 & 44.4 & 72966.7 & 0.815 & 8 & 2.31 \\
$\mathrm{~N}^{\circ} 3$ & 1974.05 & & 3 & & 89443.9 & & \\
$\mathrm{~N}^{\circ} 3$ & 1974.05 & 1.014 & 3 & 16.5 & 89443.9 & 1.068 & 6 \\
$\mathrm{~N}^{\circ} 2$ & 1946.26 & & 5 & & 83747.8 & & 2.45 \\
\hline
\end{tabular}

same with or without VOC's respecting the repeatability conditions. There were neither competition nor fibre saturation in the tested analytical range. Moreover, this test confirms the high affinity of the carboxen fiber for these volatil pollutants (Fig. 7).

\section{Test on materials}

The PVC materials were selected for their inertia when coming into contact with water.

The analysis of water in contact with the materials shows no vinyl chloride migration. But one of the 4 materials heated at $50{ }^{\circ} \mathrm{C}$ shows a vinyl chloride migration of $0.24 \mathrm{ppb}$ in a $10 \mathrm{ml}$ aqueous sample. The two conditioned waters tested also presented a vinyl chloride concentration of about $0.17 \mathrm{ppb}$ and $0.8 \mathrm{ppb}$.

\section{Discussion}

This study leads to the coming up of experimental protocol for the analysis of vinyl chloride with SPME for the analysis of water samples and materials. Obviously the Carboxen PDMS $75 \mu \mathrm{m}$ fiber presents the best affinity for vinyl chloride, as the Popp and Paschke's studies on the VOC's [20] let presage. The high sensibility of this fiber affords the utilization of lower volumes of samples which autorizes automatization. Zhang and Pawliszyn's results are similar but with $40 \mathrm{ml}$ vials [15], which may be difficult to use for control analysis. Moreover, according to Popp, the Carboxen fiber presents a poor repeatability, which is not the case for the conditions considered in the study, as the low coefficient of variation of repeatability shows.

The $\mathrm{MeOH}$ volume may not exceed $0.1 \%$ in the aqueous sample for a spiking concentration of the ppb. The $\mathrm{MeOH}$ introduced in the sample makes the vinyl chloride more soluble, which moves the partition equilibrium and decreases the adsorption on the fiber.

The upper limit of the analytical range is estimated at $200 \mathrm{ppb}$ due to the downgrading of the mass spectrum observed when vinyl chloride concentration increases. This phenomenon can be explained by the rearrangements of the vinyl chloride fragments in the trap of the spectrometer when the concentration is too high. The rearrangements level
Table V. Results of repeatability for 4 vinyl chloride concentrations.

\begin{tabular}{lcccc}
\hline $\begin{array}{l}\text { Concentration } \\
(\mathrm{ppb})\end{array}$ & $\begin{array}{c}\text { Average } \\
\mathrm{Yg}\end{array}$ & $n=$ & $\begin{array}{c}\text { Standard } \\
\text { deviation } \mathrm{Sg}\end{array}$ & $\mathrm{C.V}(\%)$ \\
\hline 0.2 & 14541 & 5 & 676.287 & 4.65 \\
0.9 & 62495.7 & 7 & 3011.2 & 4.81 \\
2 & 136897 & 4 & 5843.77 & 4.27 \\
20 & $1.023 \times 10^{6}$ & 5 & 50157.8 & 4.9 \\
\hline
\end{tabular}

Table VI. VOCs concentrations present in the sample.

\begin{tabular}{lcc}
\hline References & Compounds & Concentrations $(\mathrm{ppb})$ \\
\hline $\mathrm{CV}$ & Vinyl chloride & 20 \\
1 & Dichloromethane & 800 \\
2 & 1,1-Dichloroethene & 200 \\
3 & 1,1-Dichloroethane & 2000 \\
4 & 1,2-Dichloroethene & 9.7 \\
5 & chloroforme & 5.3 \\
6 & Trichloroethane & 2.1 \\
7 & Carbon tetrachloride & 0.6 \\
8 & Bromodichloromethane & 5.5 \\
9 & Trichloroethene & 4.1 \\
10 & Dibromochloromethane & 5.5 \\
11 & Tribromomethane & 40.1 \\
12 & Tetrachloroethene & 3.9 \\
\hline
\end{tabular}

increases with the concentration and leads to the deviation of the results.

The vinyl chloride extraction with the fiber in the headspace is ruled by two equilibrium; one concerning the liquid/gaseous phases and the other concerning the gaseous/fiber phases. To obtain a reproducible extraction, those two equilibrium have to be realised. The time required to reach those equilibrium depends on the composition of the solution, on the concentration in vinyl chloride, on the temperature, and on the stirring. The equilibrium between the steam phase and the liquid phase was reached slower than the equilibrium between the steam phase and the fiber because the distribution coefficient is much more significant in gas than in liquids. 


\section{Original articles}

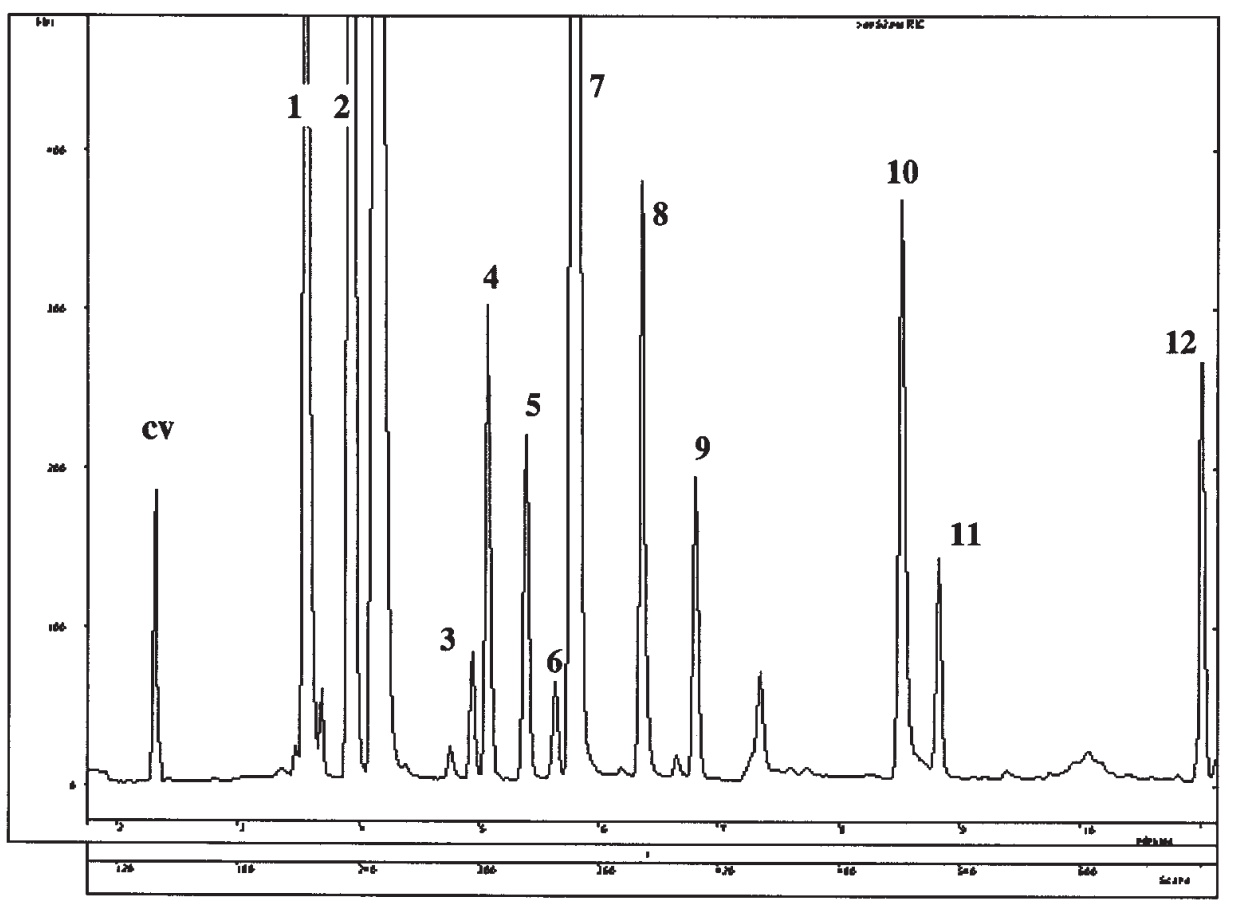

Figure 7. Analysis of a spiked sample of vinyl chloride with VOCs.
The partition equilibrium liquid/gas is the limiting factor and requires an average stirring time of $100 \mathrm{~min}$.

The time (called T95 \% is the required time to extract $95 \%$ of the compounds at equilibrium) is about $300 \mathrm{sec}-$ onds when the equilibrium liquid/gas has been reached.

In order to optimize the extraction, the quantity of vinyl chloride adsorbed was studied in terms of the variation of the sample volume. The sample volume is a parameter of the equilibrium constant calculation equation. Hence its variations have a significant influence on the compounds extraction.

$$
\begin{aligned}
& K_{\mathrm{gas} / \mathrm{liq}}=\frac{C_{\mathrm{gas}}}{C_{\mathrm{liq}}}=\frac{n_{g} \times V_{l}}{n_{l} \times V_{g}} \\
& K_{\mathrm{fiber} / \mathrm{gas}}=\frac{C_{\text {fiber }}}{C_{\mathrm{gas}}}=\frac{n_{f} \times V_{g}}{n_{g} \times V_{f}} .
\end{aligned}
$$

These equilibrium constant calculation equations demonstrate that the increase of the sample volume is in favor of the equilibrium fiber/gas. As there is saving of extraction when the sample volume increases, the partition constant between fiber and gas turns out to be clearly dominant [21]. Thanks to the exhaustion study and volume study, the partition constants $\mathrm{K}_{\text {gas/liq }}$ and $\mathrm{K}_{\text {fiber/gas }}$ were estimated respectively at 2 and 32150 . The temperature study proved that the optimum temperature is $20{ }^{\circ} \mathrm{C}$. With a lower temperature, the vinyl chloride is much present in the liquid phase whereas with a superior temperature, the increasing pressure deplete the extraction.

The tests on aqueous matrix spiked with vinyl chloride and VOCs mixture demonstrate the non-interactivity of these compounds and the possible quantification of all the family of those pollutants. Moreover, the tests on materials show that the analysis of the vinyl chloride is not even perturbed when the matrix is very complex. The water in contact with the materials remains the more representative test for the migration conditions, although in our case the ratio area/volume is too low to detect traces. A pollution of mineral and source waters was observed and can be explained by the high area/volume ratio. This kind of pollution may happen when there is long time storage and/or with high temperatures. The loose after heating is not representative of natural migration conditions, and the action of heating increases the headspace pressure which lowers the extraction of vinyl chloride.

Nevertheless, this kind of test can underline the presence of pollutants contained in the whole material and susceptible to move under different conditions.

\section{Conclusion}

After the analysis conditions optimization and according to some kind of interferent factors, it appears that the headspace SPME technique is a good method for the vinyl chloride analysis. Indeed, there is repeatability below $5 \%$ and a detection limit of $50 \mathrm{ppt}$ despite the use of a universal detector (not very sensitive) such as the mass spectrometer. This technique has to respond at the new directive on the water quality for the human consumption. It gives a maximum concentration of vinyl chloride of 500 ppt [22]. The EPA norm is 0 for the vinyl chloride concentration in drinking water (with alert rates of $0.517,0.0517,0.00517 \mathrm{mg} / \mathrm{L}$ ) and $10 \mathrm{mg} / \mathrm{l}$ in industrial wastewater [23]. Moreover, this study 
may lead to consider some interesting applications for materials and other loaded matrix.

\section{References}

1. Truffert, L. Ann. Fals. Exp. Chim. 1989, 82, 149-158.

2. Official Journal of European Community, 29 April 1981, $\mathrm{N}^{\circ}$ L167/6, Commission Directive (81/432/CEE).

3. Official Journal of European Community. Directive concerning a water quality for the human consumption (80/766/CEE).

4. Rigal, S. Wat. Sci. Tech. 1995, 31 (11), 232-237.

5. Fauris, C.; Rigal, S.; Danglot, C.; Vilaginès, R. Journal Français d'Hydrologie 1988, 19 (1), 39-49.

6. Fauris, C.; Danglot, C.; Vilaginès, R. Journal Français d'Hydrologie 1986, 17 (2), 131-142.

7. French normalisation AFNOR. XP P 41-250-2, February 1996. ICS: 13.060.40. Concerning the water quality.

8. Kontaminas, M.G.; Hatzidimitriu, E.; Voudouris, E.K. Sciences des Aliments 1985, 5, 331-340.

9. Hachenberg, H.; Schmidt, A.P. Gas chromatographic headspace analysis; London: Heyden, 1977, p 5.

10. Crompton, T.R Determination of Organic Substances in Water; vol. 2, John Wiley \& Sons, 1985.
11. EPA Method 8021. Volatile organic compounds in water by purge and trap capillary column gas chromatography with photoionization and electrolytic conductivity detectors in series.

12. Belardi, R.P.; Pawliszyn, J. Water Pollut. Res. J. Can. 1989, 24, 179.

13. Arthur, C.L.; Pawliszyn, J. Anal Chem. 1990, 62, 2145.

14. Pawliszyn, J. Solid Phase Microextraction, Theory and practice. Wiley-VCH 1997.

15. Arthur, C.L.; Pratt, K; Motlagh, S; Pawliszyn, J. LC/GC 1992, 10, 656-661.

16. Zhang, Z. and Pawliszyn, J. J. High. Resol. Chromatogr. 1996, 19,155

17. Zhang, Z. and Pawliszyn, J. Anal. Chem. 1993, 65, 1843-1852.

18. Page, D.; Lacroix, G. J. of Chromatogr. A 1997, 757, 173-182.

19. Magdic, S.; Boyd-Boland, A.; Jinno, K.; Pawliszyn, J. J. Chromatogr. A 1996, 736, 219.

20. Popp, P.; Paschke, A. Chromatographia 1997, 46, 419.

21. Gorecki, T.; Pawliszyn, J. Analyst 1997, 122, 1079-1086.

22. Official Journal of European Community, European directive related to the drinking water quality, 1998, (98/83/CEE).

23. EPA method 8260 December 1987. Gas chromatography/mass spectrometry for volatile organics: capillary column technique. 